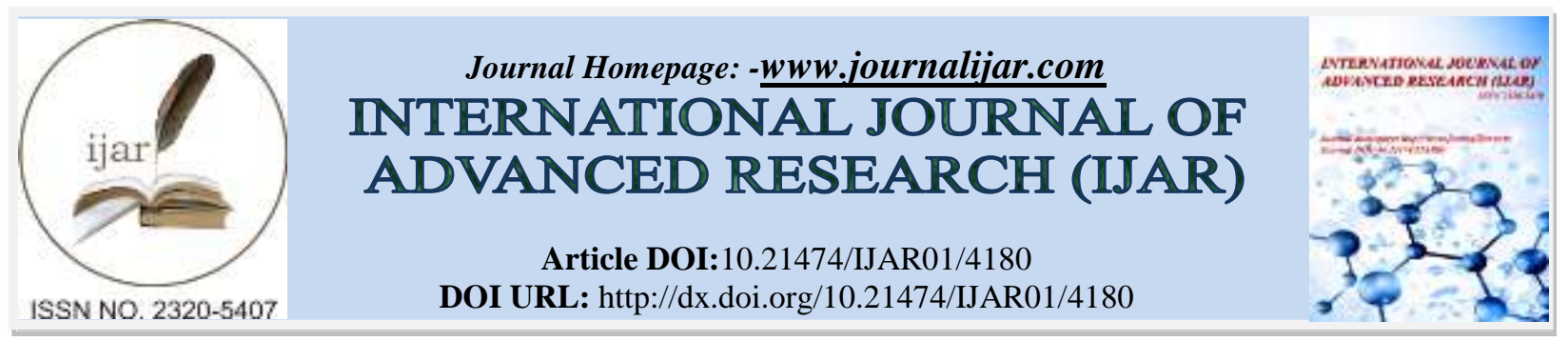

RESEARCH ARTICLE

\title{
EMBOUCHURE THERAPY: A MUSICAL WAY OF CORRECTING AN ANATOMICALLY SHORT UPPER LIP - A PILOT STUDY.
}

\section{Dr. Kiran Kumar K, Dr. Veena R, Dr. Shameem Hassainar, Dr. Vikram Kumar Jain and Dr. Smitha P.}

\section{Manuscript Info}

Manuscript History

Received: 11 March 2017

Final Accepted: 15 April 2017

Published: May 2017

Key words:-

Embouchure therapy, Circumoral musculature, Commisure height and Philtrum height.

\section{Abstract}

Embouchure is the position of lip, tongue and teeth while playing a musical wind instrument.

The Embouchure is produced with the muscles around the lips: orbicularis oris and depressor anguli oris, whilst avoiding activation of Zygomaticus major, which will produce a smile, flattening the upper lip against the maxillary anterior teeth. A short upper lip contributes to protrusion of upper incisors and represents an aesthetic concern. It is clearly possible to influence the morphology of the lips with exercise. Thus, playing a wind instrument will serve as a lip strengthening exercise and improve tooth position and soft tissue profile.

Instrument with a small aperture can help to reduce overjet and benefit the patient with a short or weak upper lip or a protruding lower lip. In accordance to functional matrix theory, the periosteal matrix such as tendons and muscles act directly upon the skeleton unit. Thus, the lip lengthening follows the functional matrix theory. In contrast, the lip exercise may be employed in to improve the morphology of the upper lip by playing wind instrument, which serves as lip lengthening, proclination correction and it also increases the lung capacity and invariably prevents mouth breathing habit.

As Orthodontists we are concerned about the "habits" but not the "hobbies" of the patient. If the patient has a hobby of playing wind instrument, it can prove beneficial to the treatment as well. Lip lengthening and open bite can be enhanced by the influence of flute embouchure in growing children.

Copy Right, IJAR, 2016,. All rights reserved.

\section{Introduction:-}

Embouchure is the position of lip, tongue and teeth while playing a musical wind instrument.

The Embouchure (fig 2,3) is produced with the muscles around the lips: orbicularis oris and depressor anguli oris, whilst avoiding activation of Zygomaticus major, which will produce a smile, flattening the upper lip against the maxillary anterior teeth.

Embouchure is an important element for tone production in flautists and also gives good exercise to circumoral muscles. This can be used by an orthodontist as an adjunct to orthodontic treatment in anatomically short upper lip and upper anterior proclination correction. 
A short upper lip contributes to protrusion of upper incisors and represents an aesthetic concern. It is clearly possible to influence the morphology of the lips with exercise. A significant increase in the height of both lips and a decrease in lip separation occur with exercise ${ }^{1}$. Thus, playing a wind instrument will serve as a lip strengthening exercise and improve tooth position and soft tissue profile.

Instrument with a small aperture can help to reduce overjet and benefit the patient with a short or weak upper lip or a protruding lower lip ${ }^{2}$.

Several functional appliances such as oral screen, frankel appliance, etc are used to maintain the balance between the teeth, its underlying bone, tongue and soft tissue component, with an anatomical short upper lip, which requires patient compliance.

In accordance to functional matrix theory, the periosteal matrix such as tendons and muscles act directly upon the skeleton unit. Thus, the lip lengthening follows the functional matrix theory.

Frankel claimed that abnormal oral and nasal function, which can be observed as an incompetent lip seal, is one of the most important etiologic factors of morphological malocclusions. Competent lip seal is obligatory for balance between buccal and tongue muscles ${ }^{3}$.

In contrast, the lip exercise may be employed in, to improve the morphology of the upper lip by playing wind instrument, which serves as lip lengthening, proclination correction and it also increases the lung capacity and invariably prevents mouth breathing habit.

While recording case history of the patient, the Orthodontist should take into consideration of any musical training that the patient is undergoing. Through this paper an hypothesis is put forward from which, the orthodontist's can be enlightened about the positive treatment outcomes by playing a wind instrument, embouchure therapy that influence lip correction, guiding of eruption of upper anterirors in proper angulation, prevents mouth breathing, increases lung capacity and even helps in openbite correction.

Mysuru is regarded as a cultural heritage and abode of music and folklore. Traditional musical instruments such as veena, sitar, tabla, and bansuri have been practiced from ages.

Lip lengthening and open bite can be enhanced by the influence of flute embouchure in growing children.

\section{Method:-}

A pilot study comprising, a study group to assess the upper lip length changes with playing flute and a control group to assess the upper lip length changes without playing flute was done in a musical institute in Mysuru, Karnataka.

Based on the eligibility criteria, the study comprised of 8 subjects in study group and 8 subjects in the control group

\section{Inclusion Criteria For Study Group:-}

$\checkmark \quad$ Subject age should be 11 yrs to 13 yrs.

$\checkmark \quad$ Subject is undergoing training since 1year.

$\checkmark$ Subject dedicates 60 to 90 minutes for learning flute in a day.

$\checkmark \quad$ Subject has anatomical short upper lip.

$\checkmark \quad$ Subject with Orthognathic profile and Angles class I molar relation.

Ethical clearance was taken prior to the study and a Consent form for the study was made to take the consent of the parent as the study sample consisted of minor age group.

The subject is assessed by two parameters:-

1. Case history

2. Clinical assessment

\section{Case History:-}

This includes a case history sheet for individual subject depicting the problem list by the subject and his/her parents. 


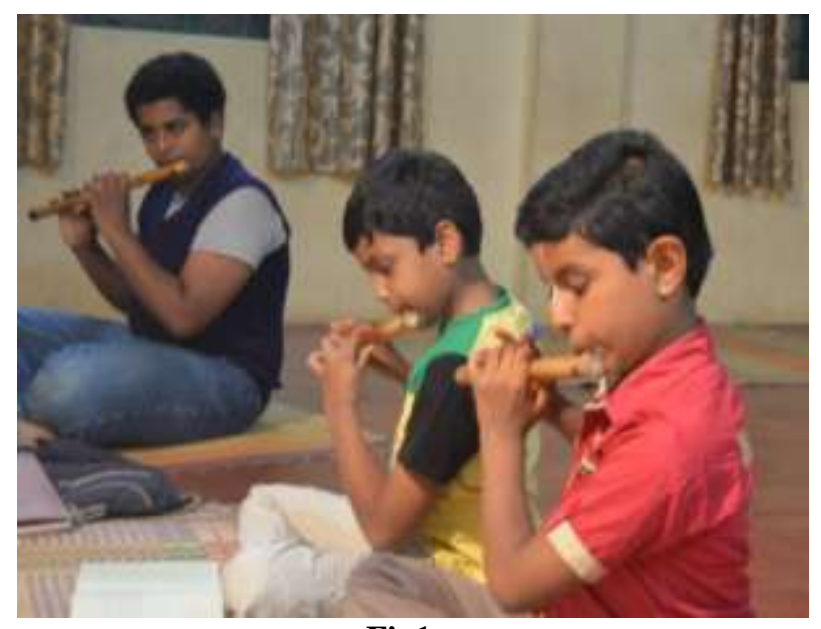

Fig1:-

\section{Clinical Assessment:-}

Each subject is clinically evaluated for anatomically short upper lip, upper anterior proclination by means of measuring philtrum and commisure height and position of lower lip to the upper incisal edge and incisor display.

Clinically, the Philtrum height is a linear measurement from soft tissue subnasale point (pt Sn) to the Upper lip Inferioris (UII) and Commisure height is measured from (Pt Sn) to angle of the mouth(fig-2).
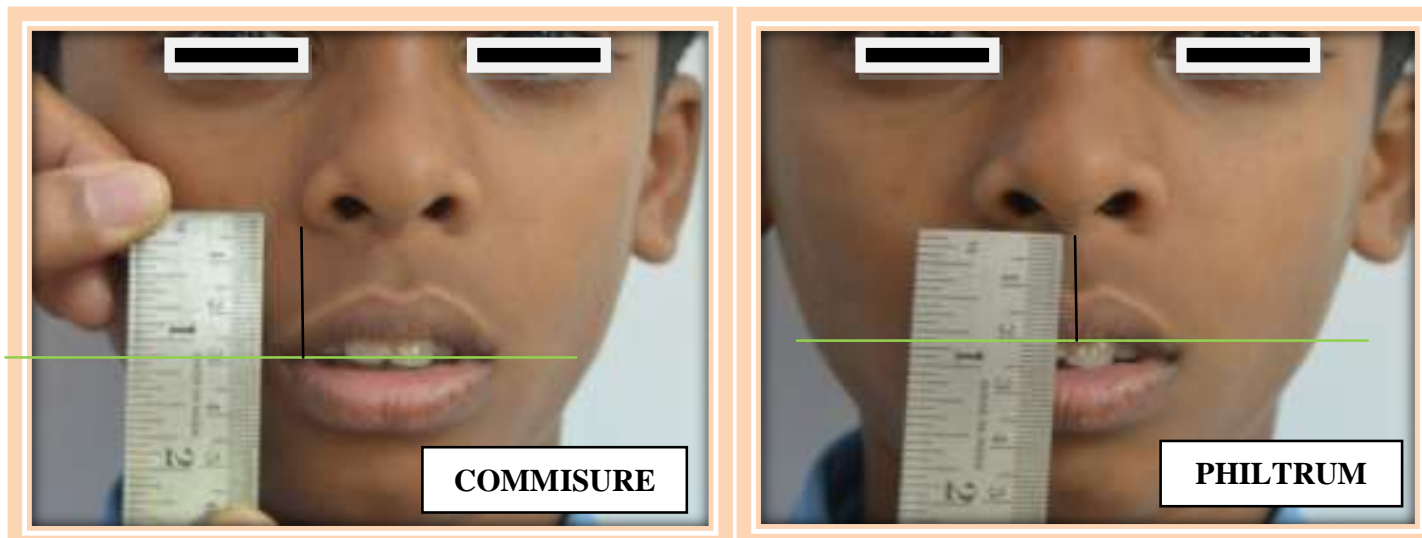

Fig 2:-

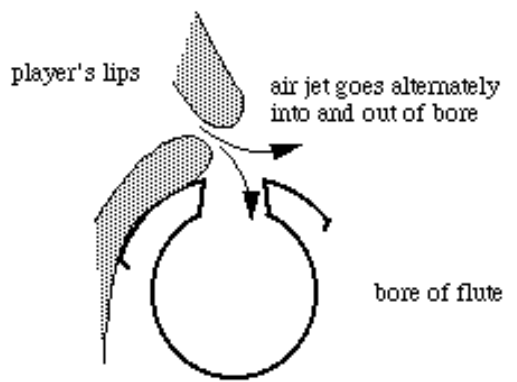

Lip embouchure

Fig 3:-

Literature says that commisure height can be 2 to $3 \mathrm{~mm}$ greater than the philtrum height, but measurement greater than that of $3 \mathrm{~mm}$ is considered as anatomically short upper lip. 
Considering the height of the upper lip, less than $19 \mathrm{~mm}$ in females and less than $22 \mathrm{~mm}$ in males is considered as anatomically short upper lip.

Increased interlabial gap of more than $3 \mathrm{~mm}$ is also considered for anatomical short upper lip.

A case record sheet was prepared to suffice the first parameter, case history and followed by clinical assessment by measuring the upper lip length by using millimeter scale.

After a span of $2 y r s$, changes in the upper lip length and interlabial gap is noted by clinical assessment.

\section{Results:-}

Data collected was subjected to Descriptive statistics using SPSS software. Results were statistically significant for study group for the philtrum height, interlabial gap and competency (fig 4,5) and (Table -1).

The commisure height of study group and control group had no significant difference.

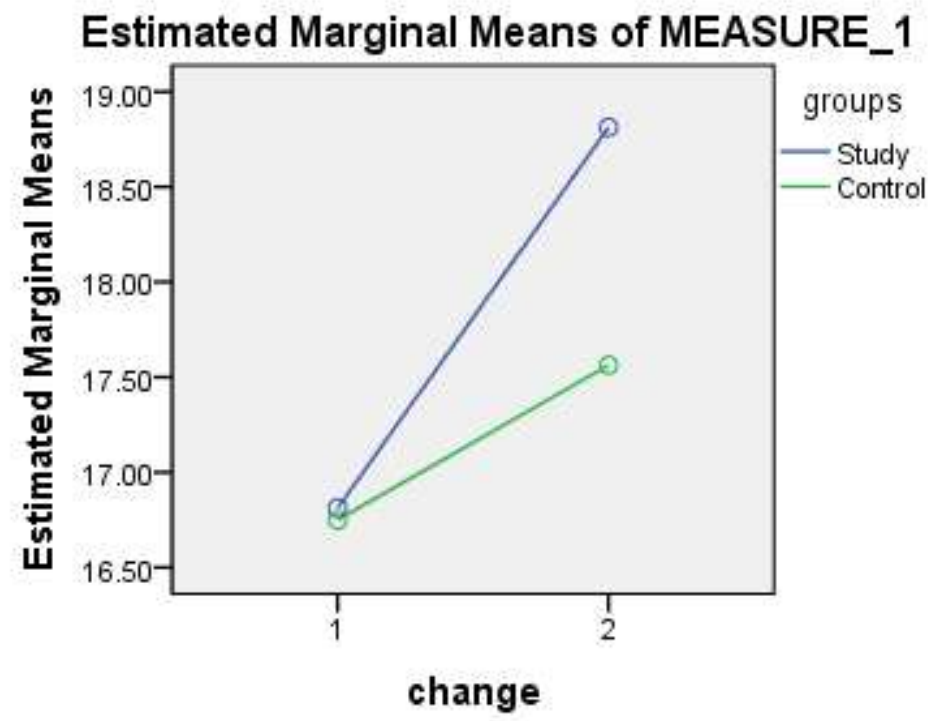

Fig 4:-

Table 1:-

\begin{tabular}{|c|c|c|c|c|}
\hline \multicolumn{5}{|c|}{ Descriptive Statistics } \\
\hline \multirow{3}{*}{ ph1 } & Groups & Mean & Std. Deviation & $\mathrm{N}$ \\
& Study & 16.8125 & 1.36113 & 8 \\
\cline { 2 - 5 } & Control & 16.7500 & 1.03510 & 16 \\
\cline { 2 - 5 } & Total & 16.7813 & 1.16860 & 8 \\
\hline \multirow{3}{*}{ ph2 } & Study & 18.8125 & 2.03430 & 8 \\
\cline { 2 - 5 } & Control & 17.5625 & 1.20823 & 16 \\
\cline { 2 - 5 } & Total & 18.1875 & 1.74045 & \\
\hline
\end{tabular}

FIG-5 


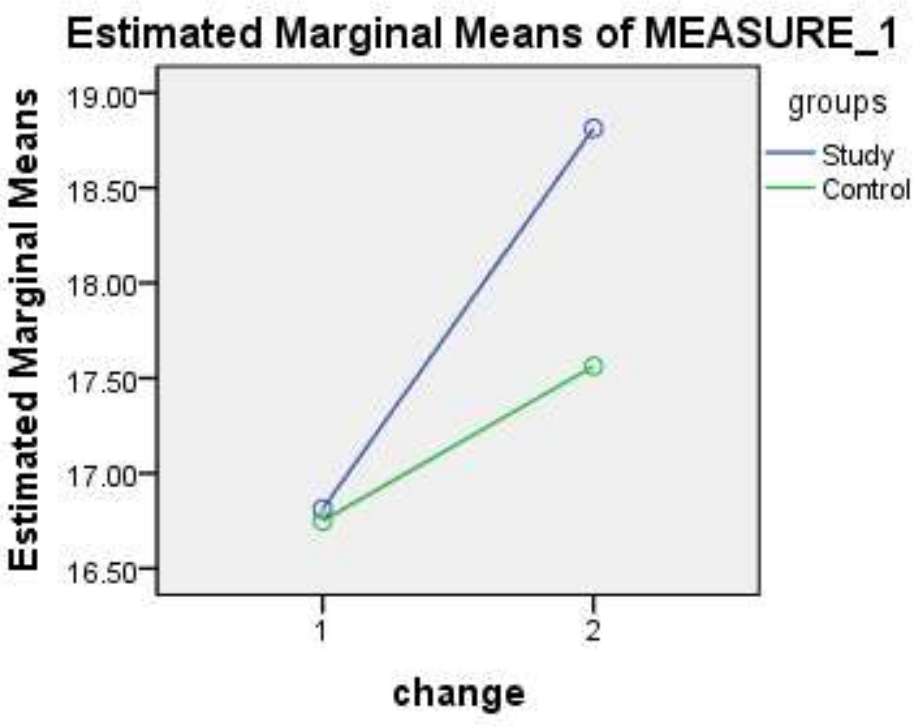

Fig 5:-

\section{Discussion:-}

Embouchure is an important element for tone production in flautists and also gives good exercise to circumoral muscles. This can be used by an orthodontist as an adjunct to orthodontic treatment in anatomically short upper lip and upper anterior proclination correction.

A short upper lip contributes to protrusion of upper incisors and represents an aesthetic concern. It is clearly possible to influence the morphology of the lips with exercise. A significant increase in the height of both lips and a decrease in lip separation occur with exercise ${ }^{1}$. Thus, playing a wind instrument will serve as a lip strengthening exercise and improve tooth position and soft tissue profile.

Through this paper an hypothesis is put forward from which, the orthodontist's can be enlightened about the positive treatment outcomes by playing a wind instrument, embouchure therapy that influence lip correction, guiding of eruption of upper anteriors in proper angulation, prevents mouth breathing, increases lung capacity and even helps in openbite correction.

Several functional appliances such as oral screen, frankel appliance, etc are used to maintain the balance between the teeth, its underlying bone, tongue and soft tissue component, with an anatomical short upper lip, which requires patient compliance.

There was a significant difference in the study group than compared to the control group. In accordance to functional matrix theory, the periosteal matrix such as tendons and muscles act directly upon the skeleton unit. Thus, the lip lengthening follows the functional matrix theory.

\section{Conclusion:-}

Lip lengthening is achieved by lip strengthening exercises in anatomically short upper lip or appliances, such as oral screen is indicated. By this pilot study a novel method for lip lengthening, short upper lip, mouth breathing habit, and open bite correction as an adjunct to Orthodontic treatment in patients who are undergoing training in music is noted.

Appliances need patient compliance but music need Interest ie, Patient compliance Vs Patient Interest. Interest is definitely better than compliance. Patient and Parent both are motivated towards the treatment without sacrificing hobbies. As an Orthodontist's, we are concerned about the "habits" but not the "hobbies" of the patient. If the patient has a hobby of playing wind instrument, it can prove beneficial to the treatment as well. Lip lengthening and open bite can be enhanced by the influence of flute embouchure in growing children. . Results were statistically 
significant for study group for the philtrum height, interlabial gap and competency. The Commisure height of study group and control group had no significant difference.

Further longitudinal study with a larger sample size is to be done to prove the hypothesis including other parameters.

\section{References:-}

1. Specific Orofacial problems experienced by musicians, Yeo et al, Australian Dental Journal: 2002; 47(1):2-11.

2. Wind Instruments: Their Interplay with Orofacial structures, James A, Howard et al, June 1989.

3. Growth changes in soft tissue facial profile, Ram S Nanda et al, The Angle Orthodontist, Vol 60, No 3. 